\title{
Assessing the effect of regional deprivation on mortality avoiding compositional bias: a natural experiment
}

\author{
Katharina Reiss, ${ }^{1}$ Ursula Berger, ${ }^{1,2}$ Volker Winkler, ${ }^{3}$ Sven Voigtländer, ${ }^{1,4}$ Heiko Becher, ${ }^{3}$ \\ Oliver Razum ${ }^{1}$
}

'Department of Epidemiology \& International Public Health, Bielefeld School of Public Health (BiSPH), Bielefeld University, Bielefeld, Germany ${ }^{2}$ Department for Medical Informatics, Biometry and Epidemiology (IBE), LudwigMaximilians-University Munich, Munich, Germany

${ }^{3}$ Unit Epidemiology and Biostatistics (EpiStat), Institute of Public Health, University Hospital Heidelberg, Heidelberg, Germany

${ }^{4}$ Section Quality of Health Care, Health Economics, Health System Analysis (GE6), Bavarian Health and Food Safety Authority (LGL), Erlangen, Germany

\section{Correspondence to} Dr Sven Voigtländer, Section Quality of Health Care, Health Economics, Health System Analysis (GE6), Bavarian Health and Food Safety Authority (LGL), Eggenreuther Weg 43 91058, Erlangen, Germany: sven.voigtlaender@ Igl.bayern.de

KR \& UB contributed equally to this paper.

Accepted 27 August 2012

Published Online First

23 October 2012

\section{ABSTRACT}

Background and objective We assessed the effect of regional deprivation on individual mortality by making use of a natural experiment: we followed up ethnic German resettlers from Former Soviet Union countries who were quasi-randomly distributed across the socioeconomically heterogeneous counties of Germany's federal state North Rhine-Westphalia (NRW).

Methods We used data from the retrospective cohort study 'AMOR' on the mortality of resettlers in NRW $(n=34$ 393). Based on the postcode of the last known residence we linked study participants to the 54 counties of NRW, which were aggregated in six deprivation clusters. Mortality rates and standardised mortality ratios (SMRs) were calculated for each cluster. After a mean follow-up of 10 years, 2580 resettlers were deceased. Results For male and female cohort members, mortality rates and SMRs were highest in the cluster 'poverty poles' (SMR men: 1.21, 95\% Cl 1.04 to 1.41; SMR women: $1.17,95 \% \mathrm{Cl} 0.99$ to 1.37 ), whereas they were lowest in the cluster 'prospering regions and suburban counties' (SMR women: $0.86,95 \% \mathrm{Cl} 0.70$ to 1.05 ) as well as in the cluster 'heterogeneous counties' (SMR men: $0.73,95 \% \mathrm{Cl} 0.61$ to 0.88 ).

Conclusions The population which was quasi-randomly distributed to counties of differing socioeconomic status experienced different levels of mortality. It was highest in regions with the highest level of regional deprivation. Previous studies describing this positive relationship between mortality and regional deprivation could not differentiate between compositional and contextual effects. Thus, our findings indicate that in terms of mortality, regional deprivation does matter.

\section{INTRODUCTION}

There is increasing interest in regional determinants of health such as the regional infrastructure, population density or regional job opportunities; factors that may have an effect on a person's health in addition to factors operating at the individual level (eg, Diez Roux ${ }^{1}$ and Razum et $a l^{2}$ ). Strohmeier et al, Klapper et $a l^{4}$ and Danke et al showed a significantly higher mortality rate in socially deprived regions of North Rhine-Westphalia (NRW) - the most heavily populated federal state of Germany. Strohmeier $e t \mathrm{al}^{3}$ investigated regional differences in morbidity and mortality by classifying the 54 counties of NRW (German: Kreise und kreisfreie Städte) into six different clusters with similar demographic and socioeconomic characteristics based on social structure indicators of each county. However, in this ecological study it does not become clear to what extent the association identified is an effect of contextual factors or merely due to the composition of the population in a particular region: people of higher socioeconomic status (and thus better health) may simply have left disadvantaged areas. ${ }^{6}$ This 'context versus composition' question is currently debated among scientists in this field.

Several authors have tried to adjust for individual characteristics by employing multilevel studies to explore the impact of contextual factors on health outcomes. They demonstrated regional effects on individual health outcomes like mortality (eg, Blomgren et $a l^{7}$ and Elstad ${ }^{8}$ ), self-rated health (eg, Franzini and Giannoni ${ }^{9}$ ) and physical health (eg, Breckenkamp et al ${ }^{10}$ and Voigtländer et $a l^{11}$ ). However, even these multilevel approaches can only account for a certain number of specified individual characteristics (eg, gender, age, social background). They can never adjust for all relevant individual characteristics (particularly not for unmeasured variables). In addition, they also do not allow us to conclude whether regional factors cause health differences or whether these health differences are due to a self-selection of individuals with similar risk profiles into specific regions. ${ }^{6}$

To rule out self-selection as a possible explanation of regional differences in health we would have to conduct an experiment in which individuals are assigned randomly to regions of residence and followed-up over time. If an individual's place of residence is selected independently of his or her demographic and socioeconomic characteristics, populations in all study regions would comprise individuals with initially similar average risk profiles who differ only regarding the exposure to contextual factors. In Germany a kind of natural experiment has taken place that models a random distribution of individuals to regions: so-called resettlers emigrated from Former Soviet Union countries to NRW between 1990 and 2001. Each year more than $90 \%$ of the resettlers came from Kazakhstan and the Russian Federation, less than $10 \%$ from Kyrgyzstan, Ukraine and Uzbekistan. ${ }^{12}$ Due to the large migration flow, Germany passed the Residence Assignment Law in 1989 (German: Wohnortzuweisungsgesetz) which assigned resettlers to a place of residence with a commitment period of 3 years. The distribution was exclusively based on the number of inhabitants and the number of migrants already allocated and it was regulated by the Resettlers Assignment Act (German: Aussiedler-Zuweisungsverordnung). Resettlers who did not adhere to the assignment 
decision or moved on during the commitment period lost their entitlement for social benefit payments and for housing. ${ }^{13}$ Counties to which the resettlers have not been assigned were not obliged to accept them as new residents. Exceptions were only made to reunite couples or parents with their children. This kind of close family reunion was the only numerically relevant reason for a self-chosen place of residence. ${ }^{14-16}$

As a result, the resettlers' initial individual health status, socioeconomic background and exposures acquired in the country of origin did not influence their place of residence. Statistically speaking, these properties have been quasi-randomly distributed over the different regions of NRW, thus constituting the closest possible approximation to the natural experiment required to disentangle the effects of composition and context. It thus allowed us to investigate the effect of regional deprivation on individual mortality, disentangling it from compositional effects. If a contextual effect on health existed, we would expect the mortality of resettlers to vary across regions.

\section{METHODS}

We based our analyses on data of the AMOR study (German: Aussiedler-MORtalitätsstudie), a retrospective cohort study on the mortality of resettlers. ${ }^{17} 18$ The cohort comprises resettlers who moved from Former Soviet Union countries to NRW. The authority responsible for the admission of resettlers in NRW (German: Landesaufnahmestelle) provided a dataset including all resettlers who moved to NRW between 1990 and 2001. For a sample of resettlers aged 15 years and older $(n=34393)$, vital status was ascertained through registration offices of the municipalities to which the resettlers had been assigned. For all cohort members, person-years were calculated as the time between date of arrival and end of follow-up (31 December 2005), date of death or date of last contact. In addition, information on sex, date of birth, date of immigration, and, where applicable, cause of death, were available.

To investigate the effect of regional deprivation on mortality among resettlers in NRW, we used the six clusters defined by Strohmeier et $a l^{3}$ These clusters have been determined by employing a main component analysis on the social, demographic and economic indicators of all 54 counties in 2002, resulting in the extraction of two factors: a factor describing the concentration of poorer, elderly, unemployed, and foreign people in regions with high population density but declining population; and an economic prosperity factor based on the disposable income. In a second step, the two factors were used to cluster the 54 counties of NRW into six categories. ${ }^{3}$ The socioeconomic status of counties tends to be stable over time periods of several years, ${ }^{19}$ which justifies the use of deprivation clusters based on information of one time point. Table 1 shows how the six clusters are characterised.

Based on the postal code of the last known residence, we determined to which of the six regional clusters each cohort member was assigned. As people might have moved and therefore might have changed clusters during the observation period, we performed an additional analysis of the cohort members' regional mobility to validate the use of the last known residence. We also analysed the mortality of resettlers, excluding persons who changed clusters, as well as of resettlers who were not assigned to a cluster at the end of the follow-up.

Age was categorised in three groups (15-39, 40-64, 65+). Sex- and age-specific mortality rates of the cohort members (deaths per 1000 person-years) were calculated for each cluster. Sex-specific standardised mortality ratios (SMRs) were also
Table 1 Clusters in North Rhine-Westphalia (NRW) based on Strohmeier et $a l^{3}$

\begin{tabular}{|c|c|c|}
\hline Cluster & Characteristics & Cities and counties \\
\hline $\begin{array}{l}\text { 1: Tertiary sector } \\
\text { cities with few } \\
\text { families }\end{array}$ & $\begin{array}{l}\text { Wealthy cities with a high } \\
\text { level of income, average } \\
\text { unemployment rate, and a }\end{array}$ & $\begin{array}{l}\text { Düsseldorf, Essen, Mülheim an } \\
\text { der Ruhr, Remscheid, } \\
\text { Solingen, Wuppertal, Bonn }\end{array}$ \\
\hline
\end{tabular}

families unemployment rate, and a lower-than-average child population

Part of the NRW population residing in this cluster in 2002: $12.7 \%$

2: Poverty poles

Deprived cities with a lower-than-average level of income, very high unemployment rate, and very high population density Part of the NRW population residing in this cluster in 2002: $9.8 \%$

3: Heterogeneous cities

Socially heterogeneous cities with an average level of income, moderate population decrease, and high unemployment rate (still below cluster 2 level) Part of the NRW population residing in this cluster in 2002: $15.5 \%$

4: Family zone

Rural districts with average level of income, high child population, population growth, and

lower-than-average unemployment rate Part of the NRW population residing in this cluster in 2002: $32.6 \%$

5: Prospering regions and suburban counties

Rural and suburban districts with a higher level of income than in cluster 4 , low unemployment rate, and a lower child population than in cluster 4

Part of the NRW population residing in this cluster in 2002: $20.1 \%$

6: Heterogeneous Less well off regions with a counties low level of income, no other common characteristics Heterogeneous structure as a result of a local government reorganisation in the 1970s leading to the unification of rural and urban districts

Part of the NRW population residing in this cluster in 2002: $9.4 \%$

calculated for each cluster, with male and female cohort members of all clusters combined as standard populations.

Due to the small number of deaths per year in some strata (age* sex*cluster), mortality rates and SMRs were averaged over the full study period of 16 years (1990-2005). The same applies to the mortality rates of the standard populations. CIs (95\%) were calculated for mortality rates and SMRs based on the logarithms of the rate as described in Breslow and Day. ${ }^{20}$

To overcome limitations of the SMR analysis and to account for age measured as a continuous variable in years as well as for sex, we also fitted a Cox proportional hazards regression model to the AMOR data (eg, Therneau and Grambsch ${ }^{21}$ and Grambsch and Therneau ${ }^{22}$ ). To correct for violation of the proportional hazards assumption, we included a non-parametric, non-linear fit for age based on p-splines. ${ }^{23}$ The Cox model 
renders mortality differences between the deprivation clusters in the form of relative risks (RR). We chose cluster 2 (poverty poles) as the reference category and used the Wald test to evaluate the significance of mortality differences. Test decisions are based on a significance value of $p<0.05$. All analyses were performed using SPSS V.17.0 and R V.2.13.

\section{RESULTS}

The AMOR cohort comprises 34393 resettlers aged 15 years and above who migrated to NRW between 1990 and 2001. The mean age at cohort entry was 40 years. The majority arrived in NRW between 1990 and 1993, with a peak in $1993(n=4190)$. At the end of the follow-up (31 December 2005), 7.5\% $(n=2580)$ of the cohort members were deceased, $89.2 \%$ were still alive and $3.3 \%(n=1138)$ were lost to follow-up. The mean observation time per cohort member was 10.1 years. The assignment to one of the six clusters could be determined for 32661 of the 34393 cohort members (95\%), resulting in a total of 329678.6 person-years. For the remaining $5 \%$ of initial cohort members, the last known residence was outside NRW. Cluster 4 (family zone) had the highest share of person-years, whereas cluster 1 (tertiary sector cities with few families) had the lowest. In almost all clusters the majority of the cohort members had arrived in NRW between 1990 and 1993. Further characteristics of the study population are shown in table 2.

\section{Mortality rates}

In almost all clusters men experienced higher mortality rates than women, independent of age. Exceptions were observed among those aged 15-39 years in cluster 1 (tertiary sector cities with few families) and those aged 65 years and older in cluster 6 (heterogeneous counties). The relative differences in mortality rates between men and women were highest in the age group 40-64 years and lowest in the age group 65 years and older.

For male cohort members, mortality rates were highest in cluster 2 (poverty poles) in the younger and in the middle age group and in cluster 5 (prospering regions and suburban counties) in the older age group. The lowest mortality rate was observed in cluster 1 (tertiary sector cities with few families) for the younger age group. For the two higher age groups lowest mortality rates were observed in cluster 6 (heterogeneous counties) (see figure 1).

The results for female cohort members were more heterogeneous. In the younger age group, the highest death rates were observed in cluster 3 (heterogeneous cities). In the middle age group mortality was highest in cluster 3 (heterogeneous cities) and cluster 4 (family zone), and in the older age group in cluster 2 (poverty poles). The lowest mortality rates in female cohort members were observed in cluster 5 (prospering regions and suburban counties) in the younger age group, and in both cluster 5 (prospering regions and suburban counties) and cluster 1 (tertiary sector cities with few families) in the middle age group. In the older age category-as with male cohort members-death rate was lowest in cluster 6 (heterogeneous counties) (see figure 1).

\section{Standardised mortality ratios}

The observed number of deaths among male cohort members was higher in cluster 3 (heterogeneous cities) and significantly higher in cluster 2 (poverty poles) than the expected value. Moreover, among male cohort members, SMRs were below 1 in cluster 5 (prospering regions and suburban counties) and significantly below 1 in cluster 6 (heterogeneous counties). Thus, the highest SMR among male resettlers was observed in cluster 2
Table 2 Characteristics of the AMOR population in North Rhine-Westphalia (NRW) at cohort entry and end of follow-up (31 December 2005)

\begin{tabular}{|c|c|c|}
\hline & $\mathbf{n}$ & $\%$ \\
\hline \multicolumn{3}{|c|}{ Characteristics of the cohort members at cohort entry (date of immigration) } \\
\hline \multicolumn{3}{|l|}{ Sex } \\
\hline Male & 16733 & 48.7 \\
\hline Female & 17660 & 51.3 \\
\hline Total & 34393 & 100.0 \\
\hline \multicolumn{3}{|l|}{ Age in years } \\
\hline $15-39$ & 19863 & 57.8 \\
\hline $40-64$ & 10954 & 31.8 \\
\hline $65+$ & 3576 & 10.4 \\
\hline Total & 34393 & 100.0 \\
\hline \multicolumn{3}{|l|}{ Immigration period } \\
\hline 1990-1993 & 14727 & 42.8 \\
\hline 1994-1997 & 11442 & 33.3 \\
\hline 1998-2001 & 8224 & 23.9 \\
\hline Total & 34393 & 100.0 \\
\hline \multicolumn{3}{|c|}{ Characteristics of the cohort members at the end of follow-up (31 December 2005) } \\
\hline \multicolumn{3}{|l|}{ Vital status } \\
\hline Alive & 30675 & 89.2 \\
\hline Deceased & 2580 & 7.5 \\
\hline Lost to follow-up & 1138 & 3.3 \\
\hline \multirow[t]{2}{*}{ Total } & 34393 & 100.0 \\
\hline & Person-years & $(\%)$ \\
\hline \multicolumn{3}{|l|}{ Sex } \\
\hline Male & 168790.3 & 48.4 \\
\hline Female & 179592.5 & 51.6 \\
\hline Total & 348382.8 & 100.0 \\
\hline \multicolumn{3}{|l|}{ Age in years } \\
\hline $15-39$ & 95255.4 & 27.4 \\
\hline $40-64$ & 175325.5 & 50.3 \\
\hline $65+$ & 77801.9 & 22.3 \\
\hline Total & 348382.8 & 100.0 \\
\hline \multicolumn{3}{|l|}{ Cluster } \\
\hline Cluster 1: tertiary sector cities with few families & 10270.8 & 3.0 \\
\hline Cluster 2: poverty poles (Ruhr area) & 36296.1 & 10.4 \\
\hline Cluster 3: heterogeneous cities & 68066.1 & 19.5 \\
\hline Cluster 4: family zone & 145189.3 & 41.7 \\
\hline Cluster 5: prospering regions and suburban counties & 31500.2 & 9.0 \\
\hline Cluster 6: heterogeneous counties & 38356.1 & 11.0 \\
\hline Outside NRW & 18704.2 & 5.4 \\
\hline Total & 348382.8 & 100.0 \\
\hline
\end{tabular}

(poverty poles), and the lowest in cluster 6 (heterogeneous counties) $(1.21,95 \%$ CI 1.04 to 1.41 vs $0.73,95 \%$ CI 0.61 to 0.88$)$ (see figure 2).

Among female cohort members no cluster showed significant deviations in SMRs from the standard population. Nevertheless, the observed number of deaths was lower than the expected number of deaths in both cluster 5 (prospering regions and suburban counties) and cluster 6 (heterogeneous counties). As with male cohort members, the highest SMR was observed in cluster 2 (poverty poles) $(1.17,95 \%$ CI 0.99 to 1.37). The lowest SMR among female cohort members was observed in cluster 5 (prospering regions and suburban counties) $(0.86,95 \%$ CI 0.70 to 1.05$)$ (see figure 2$)$.

Cohort members who moved outside NRW $(n=1732)$ experienced a lower mortality compared to those still living in the federal state (SMR men: $0.62,95 \%$ CI 0.47 to 0.84 ; SMR women: $0.90,95 \%$ CI 0.71 to 1.14 ).

The analysis on the moving behaviour showed that in the study period 1990-2005, approximately 9\% $(n=3180)$ of the 
Figure 1 Sex- and age-specific mortality rates of male and female cohort members in North Rhine-Westphalia, by cluster. Vertical lines denote $95 \% \mathrm{Cl}$. Note different scales on y-axes. C1: tertiary sector cities with few families, C2: poverty poles (Ruhr area), C3: heterogeneous cities, C4: family zone, C5: prospering regions and suburban counties, C6: heterogeneous counties.
Age category: $15-39$ years

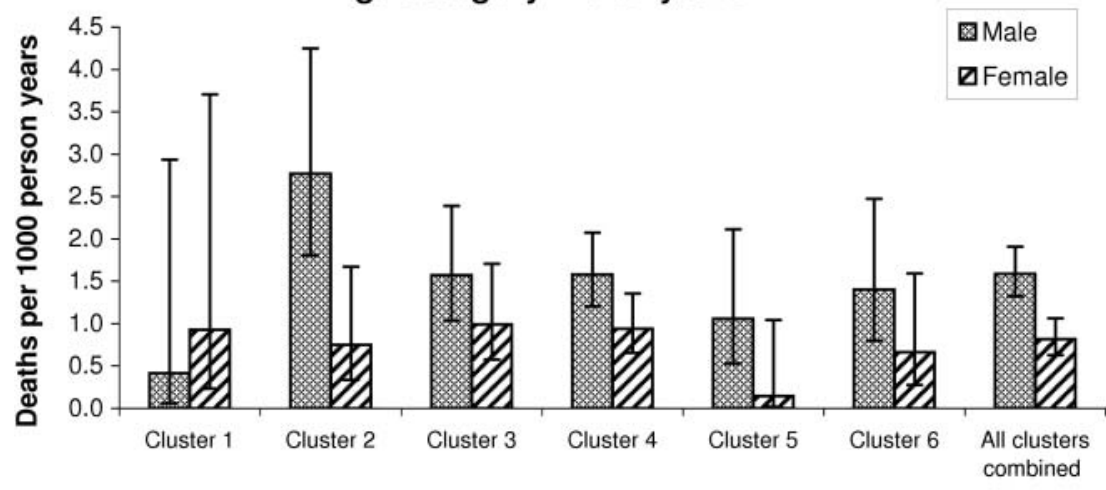

Age category: $40-64$ years



Age category: 65 years and older

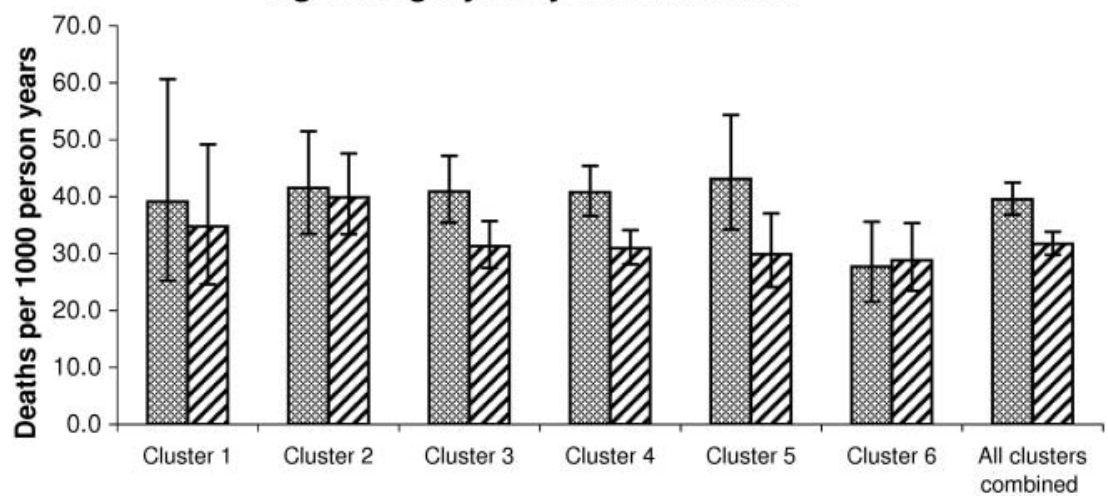

cohort members moved between clusters. No information can be provided on their length of stay in the previous cluster(s). A sensitivity analysis without those who moved between clusters resulted in a slightly higher mortality (both mortality rates and SMRs), indicating that mobile people are healthier. However, the regional variation across clusters remained the same.

The results of the Cox model confirm the findings of the analyses of mortality rates and SMRs: mortality was highest in cluster 2 (poverty poles) and lowest in cluster 5 (prospering regions and suburban counties) and cluster 6 (heterogeneous counties), where mortality was significantly reduced by $18 \%$ and $23 \%$, respectively (see table 3 ). Also in cluster 4 (family zone), mortality was significantly lower than in cluster 2 (poverty poles), with a reduction in the relative risk by $13 \%$.

\section{DISCUSSION}

In this study we examined contextual effects on mortality using the natural experiment of a quasi-random allocation of resettlers in NRW. We found a clear regional variation in mortality of resettlers according to contextual factors describing the social, demographic and economic state of the respective region they were assigned to (such as population density, unemployment rate or disposable income). Mortality was highest in the poverty poles of the 'Ruhr area' (cluster 2), the cluster with the highest level of regional deprivation. This confirms results from studies in the general population of NRW, which also found the mortality to be highest in the 'Ruhr area' ${ }^{3} 42425$ Low mortality among resettlers was observed in a cluster comprising heterogeneous counties which are composed of rural and urban districts as a result of a restructuring policy of the counties in the 1970s (cluster 6). Those counties are less well off but do not have any other common characteristics. Low mortality was also found in wealthier prospering regions and suburban counties (cluster 5). In studies investigating mortality of the general population of NRW, the cluster comprising heterogeneous counties (cluster 6) belonged to the upper midfield in terms of mortality, whereas in the cluster of wealthier prospering regions and suburban counties (cluster 5), mortality was also among the lowest. ${ }^{3} 26$ However, these studies are 
Figure 2 Sex-specific standardised mortality ratios of male and female cohort members in North

Rhine-Westphalia, by cluster. Vertical lines denote $95 \% \mathrm{Cl}$. C1: tertiary sector cities with few families, C2: poverty poles (Ruhr area), C3: heterogeneous cities, C4: family zone, C5: prospering regions and suburban counties, C6: heterogeneous counties.

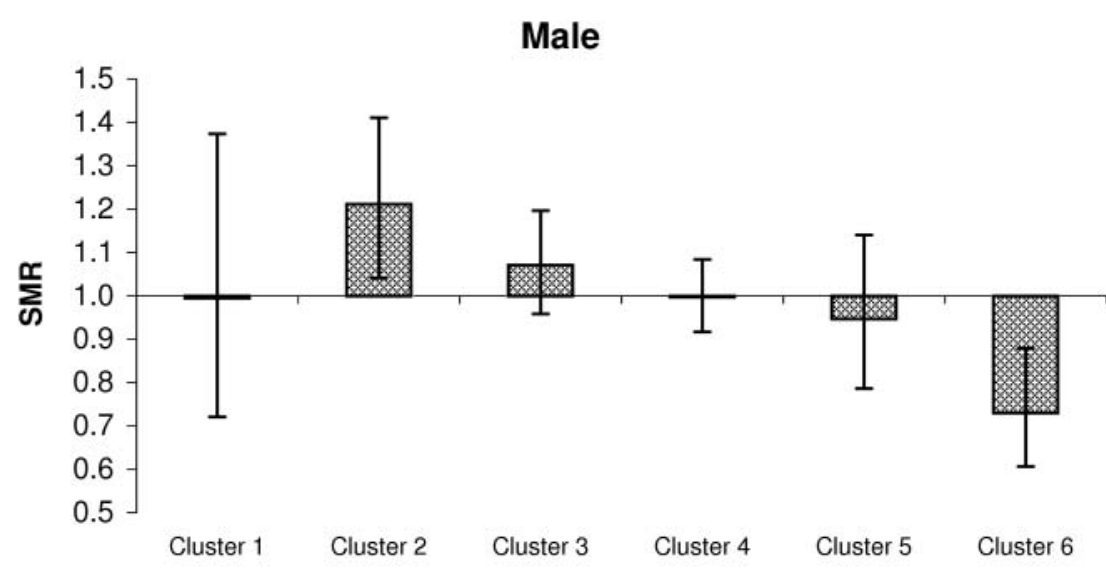

Female

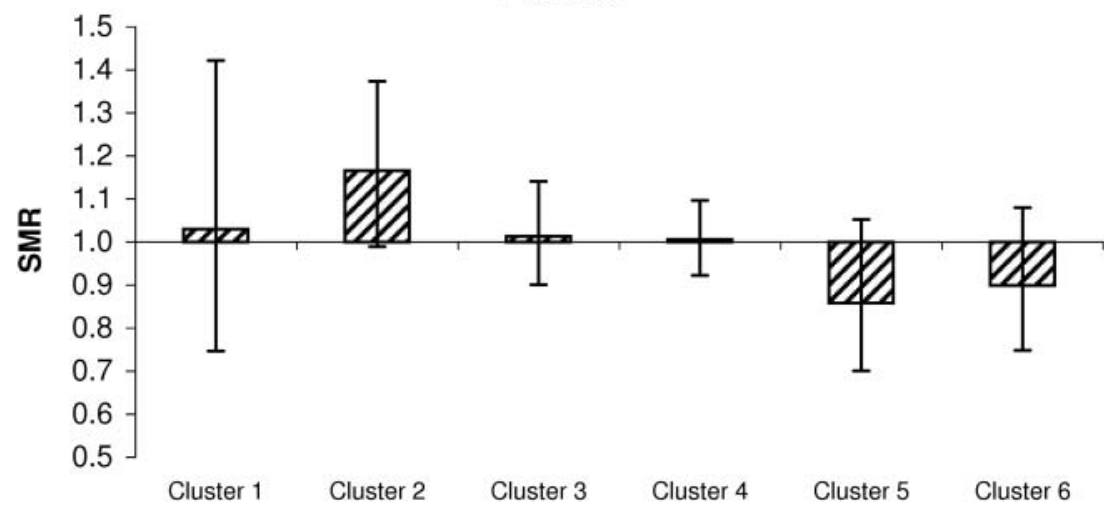

based on regional mortality data, which is subject to selection effects: individuals with certain characteristics might be selfselected into certain regions.

The database we have used provides the exceptional situation of a natural experiment, namely a quasi-random allocation of resettlers to a place of residence. Thus, the exposures, risks and resources that they acquired during their respective life courses in their countries of origin are distributed randomly throughout NRW. Moreover, the Residence Assignment Law allowed resettlers to move away from their assigned residence only after a commitment period of 3 years. Those wanting to change their place of residence within the commitment period had to apply for a special permission which was always very timeconsuming and not always successful. Our analysis of the moving behaviour confirms that resettlers move mainly within cities or municipalities. ${ }^{27}$

Since resettlers are quasi-randomly allocated to the regional deprivation clusters and tend to stay in those, no regional differences in mortality would be expected unless contextual

Table 3 Cox proportional hazards model, adjusting for sex and age (in years)

\begin{tabular}{lll}
\hline Cluster & RR (95\% CI) & p Value \\
\hline Cluster 1: tertiary sector cities with few families & $0.90(0.70$ to 1.16$)$ & 0.410 \\
Cluster 2: poverty poles (Ruhr area) & Ref. & \\
Cluster 3: heterogeneous cities & $0.88(0.77$ to 1.01$)$ & 0.070 \\
Cluster 4: family zone & $0.87^{*}(0.77$ to 0.99$)$ & 0.032 \\
Cluster 5: prospering regions and suburban counties & $0.82^{*}(0.68$ to 0.98$)$ & 0.025 \\
Cluster 6: heterogeneous counties & $0.77^{*}(0.66$ to 0.92$)$ & 0.003 \\
\hline
\end{tabular}

*Indicates a significant difference in mortality $(p<0.05)$. factors have an effect on mortality rates. However, in our quasi-experimental study we found a clear variation in the mortality of resettlers by cluster type.

A potential critique may be that the analysis of regional effects necessitates controlling for individual level confounders. However, in this study the quasi-random allocation accounts for this and therefore we may assume that immediately after allocation, resettlers of different clusters did not differ in terms of compositional variables, for example average individual socioeconomic status. Differences in social mobility after allocation would be a result of differential exposure to regional deprivation. It is possible that the observed regional effects may be partly due to individual status differences but, if so, they would have developed after the allocation and as such they would be an intermediary step and not a confounder. ${ }^{1}$

Resettlers are not representative for the general population of NRW or for Germany as a whole. Besides having different sociodemographic characteristics, they could also be more or less vulnerable to contextual effects compared to the majority population of Germany. However, it is unlikely that the observed effect of contextual factors on mortality should be restricted to resettlers only and not apply to the general population of NRW. Other studies on the general population found associations between health and regional context: poorer regions showed a poorer average health status. $^{6-8} 10$ Still, these studies had the problem of not being able to differentiate between effects of 'context versus composition'. Our study can make this distinction and provides evidence of a causal effect of regional factors on health.

Could the results be biased by resettlers who were not assigned to a cluster at the end of the follow-up ( $n=1732$; $5 \%$ of 34.393$)$ ? Assuming that mobile resettlers are healthier, 
our mortality rates and SMRs could be overestimated. The mortality of the resettlers who were not assigned to a cluster was indeed lower compared to those who were, but the size of bias is expected to be small since the number of people not assigned to a cluster is also small.

Furthermore, no information is available on length of stay per cluster in case of moving. Although the proportion of people who moved between clusters is rather small (9\%), it is still possible that the person-years of a specific cohort member were assigned to a cluster where this person did not spend most of the time between 1990 and 2005. Also, the time period between exposure to particular contextual factors and its effects on mortality can be debated. Still, a mean observation time of 10 years should be long enough to show the effect regional factors have on health.

When assessing the SMR, it has to be kept in mind that, for example, the 'family zone' (cluster 4) had the highest share of person-years $(41.7 \%)$. Thus, it also comprises a high proportion of the standard population, which results in SMRs closer to one. This problem is overcome by the Cox analysis, where RR quantify the differences in mortality between the six different clusters.

In summary, due to the quasi-random allocation of persons to counties with different levels of regional deprivation, our findings contribute to the discussion of 'context vs. composition' by demonstrating that regional factors do influence mortality.

\section{What is already known on this subject}

- Several studies indicate that regional factors have an effect on mortality which is independent of individual factors.

- It remains unclear to what extent the observed association is a true effect of regional factors or due to selection processes of individuals with certain individual characteristics into regions.

\section{What this study adds}

- Our study uses a natural experiment to test the hypothesis that regional mortality differences are at least partly due to regional effects.

- A population which was quasi-randomly distributed across Germany's federal state North-Rhine Westphalia did show regional variation in mortality after 10 years of observation.

\section{Policy implications}

- The effect of regional deprivation on mortality may be substantial; in this study it is associated with an excess mortality of around $20 \%$. It needs to be investigated whether policies aiming at a more equal distribution of resources can mitigate this effect.

Contributors $\mathrm{OR}$ and $\mathrm{HB}$ conceived the study. $\mathrm{HB}$ und $\mathrm{VW}$ provided the data. $\mathrm{KR}$, UB, SV and OR developed the analysis strategy. KR and UB carried out the study. VW and SV participated in the data analysis. KR, UB and SV drafted the manuscript. OR coordinated the study. All authors read and approved the final manuscript.

Funding This study was partly funded by the German Research Foundation (German: Deutsche Forschungsgemeinschaft), grant number RA889/2-1. The AMOR study was funded by the German Research Foundation, GRK (postgraduate programme) 793.

\section{Competing interests None}

Provenance and peer review Not commissioned; externally peer reviewed.

\section{REFERENCES}

1. Diez Roux AV. Investigating neighborhood and area effects on health. Am J Public Health 2001;91:1783-9.

2. Razum 0, Altenhöner T, Breckenkamp J, et al. Social epidemiology after the German reunification: East vs. West or poor vs. rich?. Int J Public Health 2008;53:13-22.

3. Strohmeier KP, Schultz A, Bardehle D, et al. Health indicator-based cluster analysis of districts and urban districts in North Rhine-Westphalia. Gesundheitswesen 2007;69:26-33.

4. Klapper A, Bardehle D, Razum 0. Age- and sex-specific mortality in the Ruhr region from 1994 to 2004. Gesundheitswesen 2007;69:521-6.

5. Danke K, Blecher C, Bardehle D, et al. Small area analysis of infant mortality in Bielefeld with special consideration of the migration status of parents, 2000-2006. Gesundheitswesen 2008;70:624-30.

6. Norman P, Boyle P, Rees P. Selective migration, health and deprivation: a longitudinal analysis. Soc Sci Med 2005;60:2755-71.

7. Blomgren J, Martikainen $P$, Mäkelä $P$, et al. The effects of regional characteristics on alcohol-related mortality-a register-based multilevel analysis of 1.1 million men. Soc Sci Med 2004;58:2523-35.

8. Elstad Jl. Does the socioeconomic context explain both mortality and income inequality? Prospective register-based study of Norwegian regions. Int J Equity Health 2011;10:7.

9. Franzini L, Giannoni M. Determinants of health disparities between Italian regions. BMC Public Health 2010;10:296.

10. Breckenkamp J, Mielck $A$, Razum 0. Health inequalities in Germany: do regional-level variables explain differentials in cardiovascular risk?. BMC Public Health 2007;7:132.

11. Voigtländer $\mathbf{S}$, Berger $U$, Razum 0 . The impact of regional and neighbourhood deprivation on physical health in Germany: a multilevel study. BMC Public Health 2010;10:403.

12. Bundesministerium des Innern Migrationsbericht 2010. Berlin: Bundesministerium des Innern, 2012.

13. Bundesamt für Migration und Flüchtlinge . Abschlussbericht: Zuwanderung und Integration von (Spät-)Aussiedlern-Ermittlung und Bewertung der Auswirkungen des Wohnortzuweisungsgesetzes. Nürnberg: Bundesamt für Migration und Flüchtlinge, 2007.

14. Heller W. Integration von Aussiedlern und anderen Zuwanderern in den deutschen Arbeitsmarkt. Göttingen: Bundesministerium für Raumordnung, Bauwesen und Städtebau, 1993.

15. Swiaczny F. Aussiedler-Migration und räumliches Verhalten dargestellt am Beispiel der Stadt Mannheim. In: Wendt H Zuwanderung nach Deutschland. Prozesse und Herausforderungen. Materialien zur Bevölkerungswissenschaft lHeft 94). Wiesbaden: Bundesinstitut für Bevölkerungsforschung, 1999.

16. Ködderitzsch P. Zur Lage, Lebenssituation, Befindlichkeit und Integration der rußlanddeutschen Aussiedler in Berlin. Frankfurt am Main: Peter Lang, 1997.

17. Becher H, Razum O, Kyobutungi $\mathrm{C}$, et al. Mortality of immigrants from the former Soviet Union: results of a cohort study. Dtsch Arzteb/ 2007;104:A-1655.

18. Winkler V, Ott JJ, Holleczek B, et al. Cancer profile of migrants from the Former Soviet Union in Germany: incidence and mortality. Cancer Causes Control 2009;20:1873-9.

19. Dorling D, Mitchell R, Shaw M, et al. The ghost of Christmas past: health effects of poverty in London in 1896 and 1991. BMJ 2000;321:1547-51.

20. Breslow NE, Day NE. Statistical Methods in Cancer Research. Volume II: The Design and Analysis of Cohort Studies. IARC Scientific Publications, No. 82. Lyon: International Agency for Research on Cancer, 1987.

21. Therneau T, Grambsch P. Modeling survival data: extending the Cox Model. New York: Springer, 2000.

22. Grambsch $\mathbf{P}$, Therneau T. Proportional hazards tests and diagnostics based on weighted residuals. Biometrika 1994; 81:515-26.

23. Eilers PHC, Marx BD. Flexible smoothing with B-splines and penalties. Statist SCi 1996;11:89-121.

24. Heins F, Stiens G. Regionale Unterschiede der Sterblichkeit-Untersuchung am Beispiel der Länder Nordrhein-Westfalen und Rheinland-Pfalz. Seminare, Symposien, Arbeitspapiere. Bonn: Bundesforschungsanstalt für Landeskunde und Raumordnung, 1984.

25. Landesinstitut für Gesundheit und Arbeit des Landes Nordrhein-Westfalen (LIGA.NRW). Gesundheitliche und soziale Lage der Bevölkerung im Ruhrgebiet. Düsseldorf: Landesinstitut für Gesundheit und Arbeit des Landes Nordrhein-Westfalen, 2006

26. Landesinstitut für Gesundheit und Arbeit des Landes Nordrhein-Westfalen (LIGA.NRW). Regionale Unterschiede ausgewählter Gesundheitsindikatoren in NRW, 2002. Düsseldorf: Landesinstitut für Gesundheit und Arbeit des Landes Nordrhein-Westfalen, 2005.

27. Mammey U. Segregation, regionale Mobilität und soziale Integration von Aussiedlern. In: Bade K, Oltmer J Aussiedler: deutsche Einwanderer aus Osteuropa (IMIS-Schriften, Band 8). Göttingen: V \& R Unipress, 2003. 